\title{
Experimental and theoretical analysis of the carrier induced red-shifted FM-response of /4-shifted MQW DFB LD
}

Steinmann, Martin J; Pedersen, Rune Johan Skullerud; Kotaki, Yuji

Published in:

Proceedings of the 13th IEEE International Semiconductor Laser Conference

Publication date:

1992

Document Version

Publisher's PDF, also known as Version of record

Link back to DTU Orbit

Citation $(A P A)$ :

Steinmann, M. J., Pedersen, R. J. S., \& Kotaki, Y. (1992). Experimental and theoretical analysis of the carrier induced red-shifted FM-response of /4-shifted MQW DFB LD. In Proceedings of the 13th IEEE International Semiconductor Laser Conference (pp. 172-173). IEEE.

\section{General rights}

Copyright and moral rights for the publications made accessible in the public portal are retained by the authors and/or other copyright owners and it is a condition of accessing publications that users recognise and abide by the legal requirements associated with these rights.

- Users may download and print one copy of any publication from the public portal for the purpose of private study or research.

- You may not further distribute the material or use it for any profit-making activity or commercial gain

- You may freely distribute the URL identifying the publication in the public portal 


\title{
Experimental and Theoretical Analysis of the Carrier Induced Red-Shifted FM-Response of $\lambda / 4$-Shifted MQW DFB LD
}

\author{
Martin J. Steinmann, Rune J.S. Pedersen and Yuji Kotaki* \\ Technical University of Denmark, Electromagnetics Institute \\ Center for Broadband Telecommunications, DK - 2800 Lyngby, Denmark, FAX +45 45931634 \\ * On leave from Fujitsu Labs Ltd., Atsugi, Japan
}

The FM-response of 3-section $\lambda / 4$-shifted DFB lasers has been investigated theoretically and experimentally considering spatial hole burning. A perfect agreement between experimental results and our theoretical simulations is demonstrated.

The red-shifted FM response due to spatial hole burning of three-section $\lambda / 4$-shifted DFB lasers with AR coated facets [1] (fig.1) has been analyzed for the first time. The FM response for a modulation current with the frequency $f_{m}=10 \mathrm{MHz}$ applied to the center section has been measured and calculated in the case of uniform as well as non uniform bias. An excellent agreement between the theoretical results obtained using the simulation tool CLADISS [2] and our experimental data has been observed.

First, in order to demonstrate the capabilities of the model the theory is applied to a case where spatial hole burning causes a phase shift of $180^{\circ}$ of the FM response: The side section current is kept constant and the center current is swept over its possible range (fig.2). Experimentally as well as in our simulations the laser goes towards multimode operation for too low center currents with a correspondingly high FM sensitivity. By decreasing the relative depletion of carriers in the vicinity of the $\lambda / 4$ phase shift by increasing the center current the FM sensitivity decreases but remains red-shifted. For a certain value of the center currerit a pronounced dip in the FM sensitivity is observed and the phase of the response changes from red-shif: to blue-shift. The evolving blue-shifted FM response saturates and stable single mode operation is observed even for high center currents.

Second, under normal operating conditions applying approximately uniform bias $\left(\mathrm{I}_{\mathrm{S}} \cong \mathrm{I}_{\mathrm{C}}\right)$ the carrier induced FM response is red-shifted over the whole current range due to the strong spatial hole burning (fig.3). By enhancing the spatial hole burning, i.e. by adjusting the ratio $\left(\mathrm{I}_{\mathrm{S}} / \mathrm{I}_{\mathrm{c}}\right)$ between the two bias currents, the $1 \mathrm{FM}$ sensitivity can be increased. For high bias currents, and in particular for high side section currents as applied in the traces in figure 3, the FM sensitivity is not very dependent on variations of the bias current which is advantageous in systems applications.

The fact that the carrier induced FM response is red-shifted for low center currents and blue-shifted for high center currents as pointed out in figure 2 can be verified by measuring the low-frequency FM response for several bias conditions (fig. 4\&5). At uniform bias the FM response is flat from above $10 \mathrm{GHz}$ down to DC with a phase equal to the thermal response $\left(180^{\circ}\right)$ [1]. By decreasing the spatial hole burning (e.g. $\mathrm{I}_{\mathrm{s}}=25 \mathrm{~mA}$ and $I_{c}=35 \mathrm{~mA}$ ) the magnitude of the carrier response decreases whereas the thermal response remains constant which gives rise to a drop at higher frequencies. At a certain point the phase of the carrier response changes from red-shift to blue-shift as shown in figure $4 \& 5$. A thermal dip develops in the case of a blueshifted carrier response.

In conclusion, it has been demonstrated that the theory can predict the FM response of $\lambda / 4$-shifted LFB lasers with greater accuracy than published before. It has been shown theoretically and experimentally that devices which are operated in the strong spatial hole burning regime show a red-shifted carrier induced FM response. The modulation current has hereby to be applied to that part of the structure where the strongest spatial hole burning occurs. The red-shifted carrier response eliminates the normally observed thermal dip at low frequencies and results in an flat FM response with a constant phase.

Acknowledgment: We would like to thank Prof. R. Baets and Dr. G. Morthier from Gent University for supplying the simulation tool CLADISS.

References

[1] Y. Kotaki, H. Ishikawa, Proceedings of 2nd InP and Related Materials '90, TuC.6, pp.185-188, 1990

[2] P. Wankwikelberge, G. Morthier, R. Baets, IEEE J. of Quantum Electron., QE-26, 1990, pp.1728-1741 

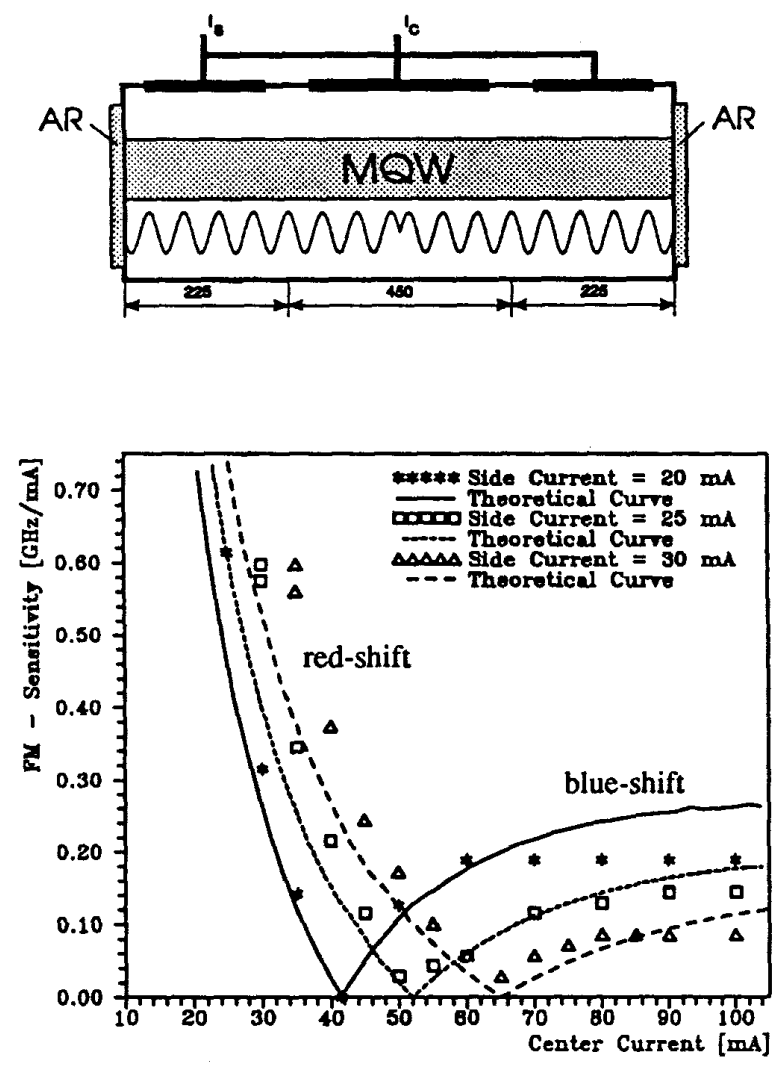

Fig.2: Experimental and theoretical FM response for a modulation frequency of $10 \mathrm{MHz}$ applied to the center section vs. center bias current. The carrier response is red-shifted on the left side of the minimum (phase $180^{\circ}$ ) and blue-shifted on the right side (phase $0^{\circ}$ ).

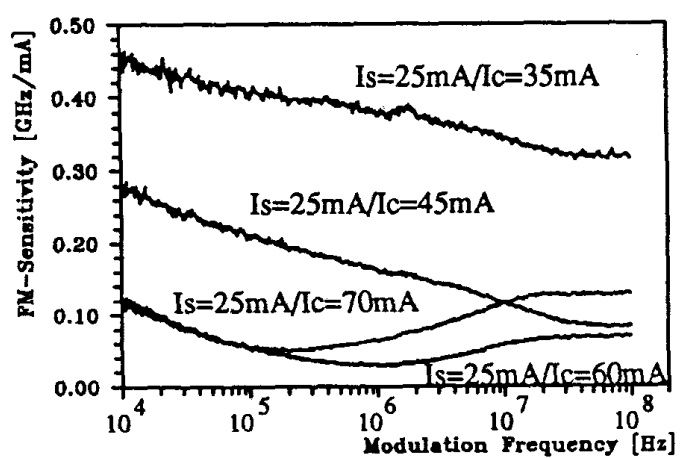

Fig.1: Structure of the investigated 3-section 2/4-shifted MQW-DFB laser with a cavity length of $\mathrm{L}=900 \mu \mathrm{m}$. The $\mathrm{KL}$ product is 2.0

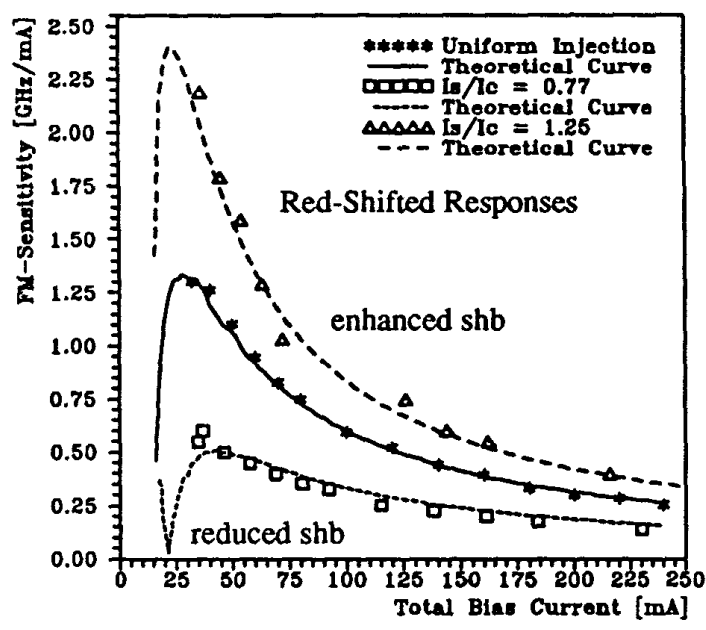

Fig.3: Experimental and theoretical FM response for $f_{m}=10 \mathrm{MHz}$ applied to the center section. The solid curve is for uniform injection. It is demonstrated that a higher FM sensitivity can be obtained by increasing the spatial hole burning (shb).

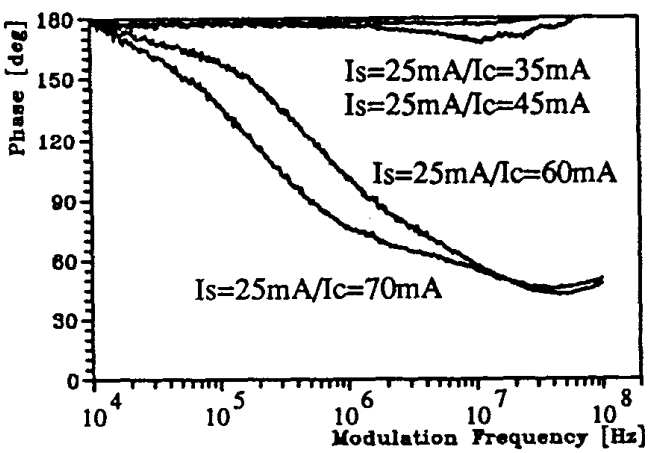

Fig.4\&5: Measured FM response for low modulation frequencies applied to the center section vs. modulation frequency for different non uniform bias conditions. It can clearly be seen that by reducing the spatial hole burning effect (by increasing the center current $I_{c}$ ) the carrier response becomes blue-shifted with a phase of $0^{\circ}$. A dip develops at the transition from the thermal intrinsically red-shifted FM response $\left(180^{\circ}\right)$ at low frequencies to the blue-shifted carrier response at high frequencies. 